\title{
The systemic perspective of service processes: underlying theory, architecture and approach
}

\author{
Luciano Batista ${ }^{1}$, Andi Smart ${ }^{2}$ and Roger Maull ${ }^{2}$ \\ ${ }^{1}$ The Open University, Open University Business School \\ Walton Hall, Milton Keynes, MK7 6AA \\ +44(0)1908654707, L.Batista@open.ac.uk \\ ${ }^{2}$ University of Exeter, School of Business and Economics \\ Streatham Court, Rennes Drive, Exeter, EX4 4PU \\ +44(0)1392263200, P.A.Smart@exeter.ac.uk, R.S.Maull@exeter.ac.uk
}

\begin{abstract}
As competition in the service industry grows, delivering high-quality service to meet customers' needs and expectations becomes paramount. In order to achieve a thorough understanding of customers, companies are increasingly adopting Customer Relationship Management (CRM) initiatives. However, CRM does not have the process reach necessary to cope with complex and cross-functional processes. This problem is better handled by Business Process Management (BPM) initiatives, which, by their turn, struggle to built-in customer intelligence in their systems. Based upon systems theory, we discuss the roles of CRM and BPM in an integrated approach to deliver customer fulfilment. As the evolution of service-oriented approaches requires us to consider both customer interactions and experiences as key elements of service processes, we present a broader perception of service processes involving these two perspectives. Also, we discuss the architecture of a customer-facing system comprising customer processes that are aimed at better dealing with customer interactions.
\end{abstract}

Keywords: Service processes, system theory, CRM/BPM integration

\section{Introduction}

In order to survive in an increasingly dynamic and complex world, many organisations are attempting to better understand the services they deliver in new ways so that they can redefine themselves to gain competitive advantage and better respond to new marketing demands (Lemak et al. 2004). There is a new service dominant logic emerging within marketing, which has developed from a focus on the exchange of goods to a broader focus on the exchange of services (Vargo and Lusch 2004). As competition in the service industry grows, delivering high-quality service to meet customers' needs and expectations becomes an important way to success (Chiu and Lin 2004). Since the added value and quality of a service is perceived by the customer, it is paramount for companies to have a thorough understanding of customer needs and expectations (Edvardsson and Olsson 1996). To achieve such a level of understanding, companies are deploying Customer Relationship Management (CRM) systems for storing customer data, managing customer interactions, and building customer intelligence. Although CRM initiatives help in establishing and maintaining valuable long-term relationship with customers, they lack visibility into the majority of existing operational processes and they cannot manage interactions between customer and operational processes (Davis 2002). There is a process gap in CRM approaches to service improvement. 
On the other hand, companies are adopting Business Process Management (BPM) initiatives to efficiently coordinate the built-in intelligence in their existing systems in order to respond with the right action at the right time to customer needs (Cameron 2003). BPM provides the platform for sharing business processes among systems, people, and partners. By adopting BPM, companies hope to design totally customer-focused business processes, integrating all the resources needed to delight customers and eliminate inefficiencies that compromise the quality of the service (Smith and Fingar 2003). However, recent research suggests that although most companies are managing processes well within local business units, just a few are successfully managing 'end-to-end' processes across business units, from first customer contact right through the fulfilment (Maddern et al. 2007). Differently from manufacturing, service processes can become invisible. Even simple processes such as approvals can become invisible when they leave one department to others work their tasks. Companies are struggling to 'surface' their service processes and manage them 'end-to-end'. To make things more complex, customer-facing processes are challenging to manage because they are always changing.

For achieving fulfilment, companies have been increasingly adopting CRM together with BPM initiatives. Nonetheless, the rich capabilities of both CRM and BPM practices are limited by their own spheres of automation and inaccessible silos of data in other applications (Davis 2002). While CRM and BPM approaches may help businesses to achieve operational efficiency, better customer relationships, agility and control, the ramifications of processes are still overlooked and difficult to integrate. As CRM approach needs process vision as much as BPM needs customer intelligence, it is evident that there is a lack of a holistic approach for developing service processes that effectively deliver fulfilment. The evolution of marketing towards a service-oriented approach requires us to question our underlying assumptions and consider customer interactions and experiences as key elements of service processes (Schembri 2006). We believe that service processes need to be considered under a systemic perspective which involves customer and operational processes into the same approach. In other words, companies need a systemic perspective for their service processes, converging customer management and process management capabilities and functionalities.

Accordingly, in this paper we present and describe the architecture of service processes from a holistic perspective. We propose systems theory as the theoretical framework for the service process architecture and consider an integrated CRM and BPM approach for service processes. The emphasis is on a new holistic view of service processes, a systemic perspective that integrates customer relationships and operational processes into the same business approach to deliver better services to customers. This system thinking provides coherence of understanding regarding service processes as well as consistence of service quality. System thinking helps organisations to see the wholes, perceive relationships between processes, uncover connections, expose root causes, and master complexity (Smith 2005). In the next section, we justify the need for a holistic perspective of service processes involving CRM and BPM approaches. In the sequence, we point out some of the main principles of systems theory that provide basis for a systemic perception of processes and integrated CRM and BPM approaches. Before concluding the paper, we discuss some practical implications of the systemic thinking on service processes and integrated CRM/BPM approaches. 


\section{The need for a systemic perspective}

$\mathrm{BPM}$ is a management approach aimed at analysing, improving, controlling, and managing processes with the ultimate purpose of improving the quality of production and service delivery (Elzinga et al. 1995). For Lee and Dale (1998), the main objective of BPM is to align business processes with strategic objectives and customer needs. Hence, a fundamental BPM tenet is that processes should be managed from an understanding of customer needs (Smith and Fingar 2003). A practical implication of this principle is that $\mathrm{BPM}$ requires the management of processes on an 'end-to-end' basis, from customer initial contact to the fulfilment of customer needs (Maddern et al. 2007). Such a postulate suits the service sector notion that a service process is always triggered by the customer and must provide results to a customer (Fließ and Kleinaltenkamp 2004) and, in theory, once the process is started a series of organisational resources are set in motion so that the customer gets, in the end, what he or she needs according to his or her expectation. Palmer and Cole (1995) argue that one of the main challenges of service process management is to make sure that 'customer participation takes place when, where and in the way it is needed to operate efficiently without neglecting customer satisfaction'. Yet, all too often there is a 'promise-performance' gap in service organisations, something that Balmer and Greyser (2003) refer to as a chasm that can exist between customer expectations and service delivery. Looking at BPM practices in UK Financial Services, Maddern et al. (2007) reported that although most companies are managing processes well within their business units, just a few are successfully managing 'end-to-end' processes across business units. This outcome casts doubt on the extent to which organisations are properly managing their processes on an 'end-to-end' basis.

If BPM acknowledges the 'end-to-end' nature of processes, why do service organisations adopting BPM practices still fail to deliver customer fulfilment? One potential problem might be related to the focus organisations are taking for their main business orientation. For instance, some authors in the process management literature argue that processes should be viewed as strategic assets and this requires organisations to take a process orientation (McCormack and Johnson 2001). Others point out that process thinking has become the main orientation of organisations and that a sustained focus on processes is a means of creating ongoing value for the organisation (Grover et al. 2000). If not carefully considered, these assertions might lead organisations to overemphasise focus on processes to the detriment of focus on customers. Our view is that process-oriented managerial approaches are necessary to implement customer-focused strategies. In other words, in order to deliver customer fulfilment BPM initiatives require customer-oriented strategies. These strategies, by their turn, are implemented through process-oriented operations. Consequently, to be coherent with the principle that processes should be managed from an understanding of customer needs, the main focus of service companies should be oriented towards customers. Once the predominant business mindset of an organisation is customer-focused, all subsequent operational arrangements within the organisation should be process-driven and deployed with the main purpose of delivering customer fulfilment. In short, a customer-oriented mindset should lead process-oriented actions. This seems to be a more reasonable business orientation that allows organisations to effectively align their processes with the strategic objectives of delivering customer fulfilment. In practical terms, in order to successfully deliver customer fulfilment, companies need to continuously rearrange their processes around a refreshed view of customers' needs and preferences. Competitive success depends on transforming an organisation's key processes into strategic capabilities that consistently provide superior value to the customers 
(Hammer 1996; Rheault and Sheridan 2002). How to develop such an organisational ability is one of the main challenges organisations face to deliver customer fulfilment.

From a customer-focused perspective, service delivery is an end-to-end process journey that begins with a customer interest in a specific service, requires proper identification of customer needs and preferences, develops through a series of interactions with the customer, and only has a satisfactory end if the customer feels really fulfilled. The whole journey can be summarised as a customer experience which comprises customer choices and interactions that are expected to lead to fulfilment. In this context, customer intelligence is crucial, as it provides organisations with a reference for dealing with all phases of a customer experience. In fact, customer intelligence allows organisations not only to effectively identify customer needs and preferences, but also compare performance against customer expectations. The building of customer intelligence is the main reason why organisations are adopting CRM practices and solutions. From a strategic point of view, CRM can be understood as a wide organisation's business strategy which focuses upon building customer-personalised interactions whatever the channel of contact between the organisation and its customers (Business Guide 2000). For Ling and Yen (2001), CRM should be considered as a wide strategic business process that involves the organisation as a whole, spanning across different business functions rather than just within a particular product or business unit. They add that CRM comprises a set of enabling systems that supports a business strategy to build lasting and profitable relationships with customers. A better understanding of customer needs and preferences is the way to enhance customer value and this aspect is one of the major objectives of CRM. A central practice in CRM strategy is to exploit customer insight and information to create profitable customer relationships (Abbott et al. 2001). In practice, each customer interaction produces extensive data. The purpose of CRM is to make inferences over this data in order to allow an organisation to identify patterns of customer behaviour as well as to identify customers' profiles, needs and preferences. For achieving continuous improvement, an organisation should track the results of customers' interactions and use such knowledge to refine further actions (Ling and Yen 2001). A major problem is that the translation of customer intelligence into action is a process issue that goes beyond the CRM sphere and reaches the BPM realm again.

Taking into account the issues addressed thus far, we can fairly infer that companies might be failing to deliver customer fulfilment because, for implementing their service processes, they are adopting BPM concepts and practices that lack customer intelligence. On the other hand, companies might be failing to properly translate customer intelligence into action because they are adopting CRM concepts and practices that lack process reach. Implementing BPM and CRM initiatives without an integrated approach might be limiting their scope of action. Figure 1 below illustrates this problem. It shows the poor results obtained by companies walking through two separate ways (non-integrated CRM/BPM approaches) with the purpose of reaching the same end (customer fulfilment). There is a clear lack of a holistic perspective to bridge the gap between both approaches so that customer fulfilment is effectively delivered.

Figure 1 - Business approach gap

[insert Figure 1 here] 
An integrated approach for CRM and BPM initiatives seems to be the most rational way for organisations to accomplish optimal results of service delivery, as customer fulfilment can be achieved by the implementation of end-to-end processes designed with basis on customer intelligence. Attempts to embed one approach into the other could be dodgy, as they could shadow the potentialities of the approach being embedded. Moreover, the scope of CRM and BPM disciplines is broad enough to not allow a total intersection of both areas. Therefore, we suggest that it is necessary to consider an integrated approach that harvests the potentialities of both CRM and BPM approaches. Service processes need customer intelligence as much as they need process performance to deliver fulfilment. Hence, service processes need to be considered in a holistic approach that integrates CRM and BPM capabilities in a way that fulfilment and performance can be efficiently and effectively implemented. In our view, such a holistic approach is feasible through a systemic perspective that takes into account CRM and BPM concepts and practices into the same framework of analysis. Naturally, systems theory provides the most appropriate framework for an integrated CRM/BPM approach for service processes.

\section{Systems theory overview}

Systems theory contributes to the investigation of behavioural phenomena in various areas of science. This is possible because it provides a set of concepts and principles that are common to all systems. The systemic paradigm has fundamentally changed the nature of scientific analysis by proposing that cause and reaction relationships take place in a more complex system of relationships and they should be analysed in terms of their relationship with a larger system (Turner 1991). As organisations can be seen as systems that interact with their external environment and receive external and internal feedback that leads to improvement in processes and outcomes, the theory has become one of the main theoretical underpinnings for the study of organisations (Lemak et al. 2004).

A primary notion is that a system is a set of parts or elements that work with each other to form a whole. It comprises complex interactions between its constituent parts. The main implication of this essential notion is that the understanding of the parts of a system is not sufficient to understand the whole. It is the interaction between elements that makes each system unique (von Bertalanffy 1968). Thus, to completely understand a system it is necessary to analyse the relationship between its parts as well as the relationship of the system with other systems. Another important notion is that a system is inherently integrative, as it entails the integration of structures, activities and interactions (von Bertalanffy 1968). The pioneering works of Wiener (1948) and von Bertalanffy (1968) provided the fundamental characteristics or qualities that are common to all systems. The fundamental characteristics that are of particular importance to the present analysis are:

- Hierarchy: Every system has a hierarchical relationship with other systems. In this sense, a system comprises a set of subsystems, and, by its turn, it is a subsystem of a greater system.

- Self-regulation: Systems have a self-organising property that guides their operations towards a determined goal. The goals or final states of systems can be very predictable and limited at lower hierarchical levels, and extremely complex at higher levels. The self-regulation of a system is enabled by feedback, which is the information that is looped back into the system to correct its deviation from course. 
- Openness: Systems are not isolated from their environment; they are open systems that have permeable boundaries that permit the exchange of material, information, and energy with their surroundings. Thus, systems affect and are affected by their environment.

- Adaptability: As systems interact with and are affected by their environment, they change and adapt themselves in order to respond to environmental conditions. This concept acknowledges the dynamic nature of systems.

The characterisation of open systems was further expanded by Katz and Kahn (1978), who developed their studies from an organisational perspective. According to them, organisations are systems open to environmental inputs and the units within an organisation affect and are affected by other units. Some common characteristics of open systems are:

- Input: Systems import some sort of energy from other system's outputs or from the external environment.

- Transformation: Systems have mechanisms or processes to transform inputs into outputs.

- Output: Systems export the transformed inputs to other systems or to the external environment.

- Steady state: Any internal or external factor that provokes disruption of the system is countered by forces which restore the system as closely as possible to its previous state. At more complex levels, systems preserve their steady state through expansion or qualitative change. A qualitative change implies quantitative growth of supportive subsystems and/or qualitative difference in the functioning of a system.

In general, an open system receives inputs from the environment that impacts on its desired objectives. As a reaction, the system adjusts its structures and processes (Katz and Kahn 1978). The role of feedback is especially important in this context. As a means to enable a proactive behaviour, feedback should be actively sought in order to initiate purposeful change in the system. Mechanisms of a feedback nature can be seen as 'learning' processes that are essential to enable purposeful behaviour of systems (Wiener 1948).

Reinforced by adjacent theories such as cybernetics (Wiener 1948; Ashby 1965), systems theory has significantly grown in scope. The general concepts we have highlighted here are particularly important for the understanding of the practical implications that we are going to discuss on the next section.

\section{Implications}

The concepts and principles addressed above offer a helpful framework for the consideration of an integrated CRM/BPM approach. Furthermore, they provide scientific basis for the appreciation of service processes under a systemic perspective. By using analogy as a method to draw practical implications from a scientific conceptual model, we can visualise some potential solutions for the problems we mentioned at the beginning of the paper.

\subsection{Integrated approach}


From a systemic perspective, CRM and BPM business approaches can be seen as two organisational systems with specific goals. While the main objective of a CRM system can be the building and updating of customer intelligence in a continual basis, a BPM system can be primarily aimed at translating customer intelligence into end-to-end processes designed to deliver customer fulfilment with minimum damage to people and cost. An integrated approach implies that CRM and BPM systems can be considered as subsystems of a greater organisational system whose main goal is to provide optimal customer experience by allowing that customer participation takes place in a way that permits the organisation to operate efficiently and affectively without neglecting customer satisfaction, from first customer contact to the conclusion of the service delivery process. In practical terms, CRM systems transform customer inputs into customer intelligence. This output of the CRM system is a valuable input for the BPM system, which can use the customer intelligence base to create new processes and rearrange existing ones so that customer requirements are constantly taken into account. The whole system can continually learn from customer feedback, which allows detection of disruption and triggers operational adjustments so that the organisation is able to more effectively respond to an ever-changing environment. These aspects are illustrated by Figure 2 below.

Figure 2 - Integrated CRM/BPM approach

[insert Figure 2 here]

It is possible to identify several systemic features in an integrated CRM/BPM approach. For instance, we are dealing with hierarchical issues when we consider CRM and BPM approaches as systems of processes working together and contributing to the achievement of the objectives of a greater organisational system. By their turn, CRM and BPM approaches can comprise a number of subsystems within the organisation. The integrative nature of systems can be observed if we consider that CRM and BPM approaches can mobilise structures, activities and interactions to the achievement of higher organisational systems whose goals are shared by different departments or functional units. More specifically, as these activities and interactions, not rarely, extend across different departments, a systemic approach that is inherently integrative might help organisations to optimise complex processes and better deal with problems of fragmented and isolated solutions. The emphasis on systems objectives shared by different departments might facilitate debate about purposes and provide mechanisms through which genuinely shared purposes can surface (Jackson 1988). This implies the practical notion of freeing management of boundary management to concentrate on systemic functions (Rice 1958). Furthermore, in order to better deal with the fact that customer-facing processes are difficult to manage because they are dynamic, we can consider that CRM and BPM approaches are supported by open systems that affect and are affected by the environment; their openness to customer feedback allows self-regulation and adaptability to new customer requirements. The development of qualitative changes in structures and processes to counteract internal and external disruptive factors is a means to preserve their steady state. Defining the steady state of systems around customer fulfilment is a way to ensure that organisational focus on customer is not neglected.

Additionally, it is possible to consider that a CRM approach requires a number of processes grouped into its sphere of action to produce specific outcomes that will contribute to the achievement of specific objectives. In this sense, the processes that 
sustain the CRM approach can be seen as the ones responsible for the continuous creation and maintenance of a customer intelligence base that will support strategic decisions aimed at developing long-term learning relationships with customers. The role of BPM approach in the articulation of those processes is paramount. BPM can be seen as the process-driven approach that 'orchestrates' the implementation of both existing and new processes aimed at observing and responding to customer requirements.

\subsection{Architecture and systemic perspective}

By definition, a process is the logical organisation of people, materials, equipments and procedures into a series of activities designed to produce a specific outcome (Davenport and Short 1990). The transformational feature of a process is more emphasised by the ISO 9000 standard, which defines a process as a 'set of interrelated or interacting activities that transform inputs into outputs' (ISO 9000:2005).

The architecture of a process actually refers to the processes that together form the organisational activity and the dynamic relationships between those processes. The architecture of a process may be seen as a subjective mapping of its elements or components to some kind of structure or system, which preserves the interactions among the components (Sommer 2004). Conversely, a process can be decomposed into greater levels of granularity which provides greater details on its constituent parts (Armistead and Machin 1997). These definitions and concepts reflect the very systemic nature of processes. Indeed, previous work has indicated that processes are analogous to systems (Smart et al. 1999). An important implication of this is that process management can be grounded in the discipline of systems and, in fact, there is a common view acknowledging the practicability of such underpinning (Rummler and Brache 1990; McHugh et al. 1995). Therefore, the systemic perspective of processes implies that the general principles and characteristics of systems, such as hierarchy, openness, adaptability, self-regulation, steady state, etc. can be fairly applied to the understanding and management of service processes.

As the evolution of marketing towards a service-oriented approach requires us to consider customer interactions and experiences as key elements of service processes (Schembri 2006), a broader perception of the service process is necessary. An expanded notion of a service process should take into account that the experience of a customer with a company actually starts before a service is actually required by the customer (Gupta and Vajic 1999) and it might continue after the service is delivered. For example, before requiring a specific service a customer may contact a company to get further information about the service and the options available for its delivery. Once the service is ordered, the customer experience progress over time through a series of interactions that may occur during the provision of the service (Vargo and Lusch 2004). As illustrated in Figure 3, the experience might continue if feedback mechanisms take place after the service is delivered.

Figure 3 - The customer experience over time

$$
\text { [insert Figure } 3 \text { here] }
$$

The complexity of this broader perception a customer experience can be better dealt with from a systemic perspective. A practical implication of the systemic premise that a system is affected by its environment would be the recognition that every customer interaction should be given special attention. In practice, some customer interactions might trigger 
events, others might enable control, and others might allow adjustments and future improvements in the service delivery system. A systemic architecture would put in place a set of customer-facing processes arranged into a system whose main goal is to deal with all customer interactions. This 'customer-facing' system of processes would be virtually situated in an organisational layer closer to the customer, as a 'front-end' sub-system composed by customer processes. The inputs to this system would be the customer interactions and the outputs from this system would be the customer inputs appropriately categorised to support other organisational processes at a managerial and operating level at the back-end. In theory, this is a functional feature of CRM systems, which are deployed to support management and operations processes with categorised customer inputs that are expected to preserve organisational focus on customer and reassure that customer needs and preferences are met. The problem is that CRM systems do not have the scope necessary to involve all processes within an organisation. This is why all process arrangements should be lead by a BPM approach, as it has the necessary scope to handle issues regarding the integration of 'front-end' with 'back-end' processes. In our view, in order to adequately integrate customer processes with back-end processes, BPM initiatives should start the designing of service processes from the processes in this customer-facing layer in a first moment. In other words, instead of start modelling how an organisation does its work internally, we should start modelling the processes that customers go through when interacting with the organisation. This notion is aimed at drawing the organisation's attention to what the total customer experience is actually like. Modelling the responses to the customer experience requirements should then follow.

The suggestion of starting the design of service processes around the needs and capabilities of the customer seems to be more coherent with the concept of customerfocused organisation than the traditional design that starts from and internal logic. In practical terms, the philosophy of a 'customer-centred' process design implies designing processes in which the needs, preferences, and limitations of the customer are given extensive attention at each stage of the design process. This requires designers to analyse and foresee how customers interact with the organisation and what are their needs and preferences before designing the internal responses. Moreover, it is not enough to understand the many distinct interactions of a customer experience; rather, the main goal is to understand how each interaction should integrate with other processes that form the customer experience as a whole. In the end, the ultimate perception a customer has of a certain service is based upon his or her perception of the experience with the system as a whole (Edvardsson and Olsson 1996).

\section{Conclusion}

In this paper we presented the main principles and concepts of systems theory that provide support to a holistic perspective and expanded perception of service processes. By making an analogy with the scientific model of systems behaviour and their main qualities, we discuss some practical implications of the systemic thinking that might help to clarify issues related to the main business focus of organisations and the roles CRM and BPM can play to support the delivery of services in a more integrated manner, which might improve organisational efficiency and effectiveness. It is important to bear in mind that CRM and BPM per se do not address the whole spectrum of issues and problems related to the comprehensive management of business processes. Our main purpose here is to develop a systemic framework that bridges the gap between these to approaches, which can be considered as an important step towards holistic managerial initiatives. 
The contextual background for our analysis considers an expanded view of service processes which takes into account that a customer experience starts before a service is ordered and might go on after the service is delivered. The importance of managing customer intelligence is emphasised and the architecture of customer processes organised in a customer-facing system is considered.

Some of the ideas developed in this paper are the fruit of theoretical exercise, and the models and solutions suggested need empirical evidence. The systemic features and practical implications addressed here certainly provide an insightful basis for future research and managerial initiatives. Indeed, our main intention here was not to conclude, but to start and motivate a thread of discussions and investigations around service processes in the light of systems theory and adjacent disciplines.

Other theoretical perspectives can expand or even reformulate the framework discussed in this paper. For instance, one can use system dynamics, which has also been influenced by cybernetics and general systems theory, as a basis to support holistic approaches of service delivery systems. System dynamics takes into account the overall interaction of the components (processes) in a system. It is mainly concerned with the understanding of the dynamics of complex systems in terms of a network of interconnected negative and positive feedback loops (Senge 1990). System dynamics concepts and tools might help the visualisation of how customer-facing processes interrelate with back-office processes through positive and negative feedback. Finally, systems theory is not exempt from criticism. Complexity theory authors argue that many management and organisational theorists lack attention to process and that they have used systems ideas to reconstitute the functional features of Taylorism (Stacey et al. 2000). They also claim that 'system' managers fail to function as expected in a turbulent world because they focus so much on stability and ignore ordinary everyday human freedom (Stacey 2001). From a complexity theory perspective, business processes are 'complex responsive processes of relating' in a social system where individuals interact for their own individual reasons based upon their previous interactions experiences (Stacey 2001). Therefore, one can attempt to develop a theoretical framework for service processes where the complexities of human interactions within the service delivery system are more explicitly accounted.

\section{References}

ABBOTT, J., STONE, M. and BUTTLE, F., 2001, Integrating Customer Data into Customer Relationship Management Strategy: an Empirical Study. Journal of Database Marketing, 8, (4), 289-300.

ARMISTEAD, C. and MACHIN, S., 1997, Implications of Business Process Management for Operations Management. International Journal of Operations and Production Management, 1, (17), 886-898.

ASHBY, W., 1965, Introduction to Cybernetics (Chapman \& Hall).

BALMER, J. and GREYSER, S., 2003, Revealing the Corporation (Routledge).

BUSINESS GUIDE, 2000, Customer Relationship Management, March Edition (Caspian Publishing). 
CAMERON, D., 2003, BPM Delivers Real-Time Business Coordination. Business Integration Journal, December 2003, pp.42-44. Available online at http://www.bijonline.com.

CHIU, H. and LIN, N., 2004, A Service Quality Measurement Derived from the Theory of Needs. The Service Industries Journal, 24, (1), 187-204.

DAVENPORT, T. and SHORT, J., 1990, The New Industrial Engineering: Information Technology and Business Process Redesign. Sloan Management Review, Summer, 31, (4), $11-27$.

DAVIS, R., 2002, The Wizard of Oz in CRMLand: CRM's Need for Business Process Management. Information Systems Management, September, 19, (4), 43-48.

EDVARDSSON, B. and OLSSON, J., 1996, Key Concepts for New Service Development. The Service Industries Journal, 16, (2), 140-164.

ELZINGA, D., HORAK, T., CHUNG-YEE, L. and BRUNER, C., 1995, Business Process Management: Survey and Methodology. IEEE Transactions on Engineering Management, 24, (2), 119-128.

FLIEß, S. and KLEINALTENKAMP, M., 2004, European Research in Service Marketing. Journal of Business Research, Volume 57, Issue 4, April 2004, pp. 392-404.

GROVER, V., KeTtinger, W. and TENG, J., 2000, Business Process Change in the $21^{\text {st }}$ Century. Business and Economic Review, Columbia, 46, (2), 14-18.

GUPTA, S. and VAJIC, M., 1999, The Contextual and Dialectical Nature of Experiences. In: J. Fitzsimmons and M. Fitzsimmons (Eds.), New Service Development (Sage).

HAMMER, M., 1996, Beyond Reengineering (Harpercollins).

ISO 9000:2005, Quality management systems — Fundamentals and vocabulary, ISO Standards collection (ISO).

JACKSON, M., 1988, An Appreciation of Stafford Beer's 'Viable System' Viewpoint on Managerial Practice. Journal of Management Studies, 25, (6), 557-573.

KATZ, D. and KAHN, R., 1978, The Social Psychology of Organizations, $2^{\text {nd }}$ Edition (John Wiley \& Sons).

LEE, R. and DALE, B., 1998, Business Process Management: a Review and Evaluation, Business Process Management Journal, 4, (3), 214-225.

LEMAK, D., HENDERSON, P. and WENGER, M., 2004, A New Look at Organizational Transformation Using Systems Theory: an Application to Federal Contractors. Journal of Business and Management, 9, (4), 407-423. 
LING, R. and YEN, D., 2001, Customer Relationship Management: an Analysis Framework and Implementation Strategies. Journal of Computer Information Systems, 41, (3), 82-98.

MADDERN, H., MAULL, R., SMART, A., BAKER, P., 2007, Customer Satisfaction and Service Quality in UK Financial Services. International Journal of Operations \& Production Management, 27, (9), 998-1019.

McCORMACK, K. and JOHNSON, B., 2001, Business Process Orientation, Supply Chain Management \& the e-Corporation. IIE Solutions, 33, (10), 33-37.

McHUGH, P., MERLI, G. and WHEELER, W., 1995, Beyond Business Process Reengineering (Wiley).

PALMER, A. and COLE, C., 1995, Services marketing - Principles and practice (Prentice-Hall).

RHEAULT, D. and SHERIDAN, S., 2002, Reconstruct Your Business around Customers. Journal of Business Strategy, 23, (2), 38-43.

RICE, A., 1958, Productivity and Social Organisation (Tavistock).

RUMMLER, G. and BRACHE, A., 1990, Improving Performance - How to Manage the White Space on the Organisation Chart (Jossey-Bass).

SCHEMBRI, S., 2006, Rationalizing Service Logic, or Understanding Services as Experience?. Marketing Theory, 6, (3), 381-392.

SENGE, P., 1990, The Fifth Discipline: The Art and Practice of the Learning Organization (Doubleday).

SMART, P., MAULL, R. and CHILDE, S., 1999, A Reference Model of 'Operate' Processes for Process-Based Change. International Journal of Computer Integrated Manufacturing, 12, (6), 471-482.

SMITH, H., 2005, What Innovation Is, CSC White Paper, Available online: http://www.csc.com/features/2004/93.shtml, accessed on: 16 Nov 2006.

SMITH, H. and FINGAR, P., 2003, Business Process Management - The Third Wave (Meghan-Kiffer).

SOMMER, R. , 2004, Architecting Cross-Functional Business Processes: New Views on Traditional Business Process Reengineering. International Journal of Management and Enterprise Development, 1, (4), 345-358.

STACEY, R., 2001, Complex Responsive Processes in Organizations: Learning and Knowledge Creation (Routledge).

STACEY, R., GRIFFIN, D. and SHAW, P., 2000, Complexity and Management - Fad or Radical Challenge to Systems Thinking? (Routledge). 
TURNER, J., 1991, The Structure of Sociological Theory (Wadsworth Publishing).

VARGO, S. and LUSCH, R., 2004, Evolving to a New Dominant Logic for Marketing. Journal of Marketing, 68, (1), 1-17.

von BERTALANFFY, L., 1968, General System Theory (George Braziller).

WIENER, N., 1948, Cybernetics, $2^{\text {nd }}$ Edition (The MIT Press). 